\title{
A study on frequency of proteinuria and its determinants among type 2 diabetes mellitus patients presenting at tertiary care hospital of North India
}

\author{
Kunal Ghosh ${ }^{1}$, Poonam Agrawal ${ }^{2, *}$, Sumita Sethi ${ }^{3}$, Kanchan Kulhari ${ }^{4}$, Niket Verma ${ }^{5}$ \\ ${ }^{1}$ Student, ${ }^{2,3}$ Associate Professor, ${ }^{4,5}$ Assistant Professor, ${ }^{2,4}$ Dept. of Biochemistry, ${ }^{3}$ Dept. of Opthalmology, ${ }^{5}$ Dept. of General \\ Medicine, ${ }^{\mathbf{1}, \mathbf{2 , 4}, \mathbf{5}}$ Army College of Medical Sciencces \& Base Hospital, Delhi Cantt, New Delhi, ${ }^{3}$ BPS Government Medial \\ College, Khanpur, Sonepat, Haryana, India
}

*Corresponding Author:

Email: drpoonam24agrawal@yahoo.com

\begin{abstract}
Type 2 diabetes mellitus is the disease which has reached epidemic proportion worldwide. Diabetic kidney disease (DKD) is an important and irreversible microvascular complication of diabetes mellitus which is characterized by persistent proteinuria, hypertension and progressive irreversible decline in renalfunction. The present study was carried out to stratify proportion of diabetic nephropathy as reflected by proteinuria, according to duration of diabetes mellitus as well as to identify the possible demographic, anthropometric and hemodynamic risk factors for the development of proteinuria. This crosssectional study was conducted on 74 patients of type 2 diabetes mellitus. Age, sex, height, weight, systolic and diastolic blood pressure and body mass index was recorded. $4 \mathrm{ml}$ of fasting venous blood was collected under aseptic precaution. Proteinuria was assessed semi quantitatively using dipsticks. All data is presented as Mean \pm SD. Unpaired student t-test was used to compare mean values of continuous variable. Total 37 out of 74 participants showed FPG 126 or more mg/dl out of which 22/37(59.5\%) showed no proteinuria but $15 / 37(40.5 \%)$ showed proteinuria. Total $14(18.9 \%)$ participants out of 74 were obese out of which $57.1 \%(8 / 14)$ did not have proteinuria while $42.9 \%(6 / 14)$ hadproteinuria. There was clear association seen in frequency of proteinuria with the duration of diabetes. $45 \%$ of patients who had diabetes for more than 10 years developed proteinuria as compared to $35.7 \%$ and $10 \%$ patients who had proteinuria for 5-10 years and less than 5 years respectively. Frequency of proteinuria in type 2 DM patients was $24.32 \%$. Predictors were BMI, FBG and duration of diabetes mellitus. Early measurements should be taken to control obesity, blood pressure and blood glucose to reduce the occurrence of diabetic nephropathy.
\end{abstract}

Keywords: Proteinuria, Type 2 Diabetes Mellitus, Diabetic nephropathy.

\section{Introduction}

Type 2 diabetes mellitus is the disease which has reached epidemic proportion worldwide. World health organization (WHO) estimates that over 170 million people worldwide are presenting with diabetes with number possibly rising to 370 million in the next 20 years (USRD, 2004). ${ }^{1}$ Situation is graver in India and it is estimated that 10 years from now 1 in every 5 diabetics will be an Indian. ${ }^{2}$ Recently our research group also has reported very high prevalence of diabetes in North India ${ }^{3}$. Many factors are responsible for such high prevalence of diabetes mellitus in India. These may range from lifestyle factors to genetic predisposition.

Diabetes mellitus disease poses an important threat to the wellbeing of the patient not only because of its own adverse effect on various metabolisms, but also because this disease predisposes various microvascular and macrovascular complications in effected individual. Diabetic kidney disease (DKD) is an important and irreversible microvascular complication of diabetes mellitus which causes significant morbidity and mortality in affected individual. DKD is characterized by persistent proteinuria, hypertension and progressive irreversible decline in renalfunction.

End stage renal disease (ESRD) is a major limiting factor for optimal treatment of such patients in developing countries like India. Hence it is important to identify the risk factors associated with occurrence of this dreaded complication in a subset of diabetic patients. Early identification of risk factor for diabetic nephropathy, timely intervention and modification of associated risk factor wherever possible helps in considerable reduction in morbidity and mortality related to this complication in diabetes mellitus. ${ }^{4}$ Several studies done in past have demonstrated that factors such as age of onset of disease, gender, obesity, blood pressure influence the progression of diabetic nephropathy. ${ }^{5-6}$ Role of these factors in occurrence of proteinuria and diabetic nephropathy in type 2 diabetic patients attending tertiary care hospital of New Delhi is studied by us.

Viswanathan $\mathrm{V}$ et al have reported that $44 \%$ of subjects who had normal function and absence of hypertension and other associated diabetic complication at the time of enrollment in the study, developed macroalbuminuria during the 12 years follow up study. ${ }^{7}$ Another similar study reported only $25 \%$ progression to persistent micro or macro albuminuria in 10 years prospective observational follow up study. ${ }^{8}$ Researchers concluded that this difference in percentage of proteinuria in two different studies may also be due to the fact that type $1 \mathrm{DM}$ was studied in later group while Type 2 DM was studied by former group of researchers. Duration of diabetes certainly play an important role in development of subclinical and overt nephropathy. 
Kohler KA et $\mathrm{al}^{9}$ and Nelson $\mathrm{RG}$ et $\mathrm{al}^{10}$ have shown significant correlation between duration of diabetes and development of microproteinuria.

Certain studies have reported higher frequency of proteinuria with increasing duration of diabetes mellitus. ${ }^{11-12}$ Many studies have shown the role of other factors like obesity, hypertension in occurrence of this complication. Tefera $\mathrm{G}$ has reported $13.8 \%$ frequency of proteinuria in type $2 \mathrm{DM}$ patients with age, obesity, duration, hypertension being significant predictor of this complication. ${ }^{13}$ In observational follow up study done by Viswanathan $\mathrm{V}$ et al uncontrolled DM along with mean higher SBP emerged as significant factor for development of proteinuria. ${ }^{7}$ Studies have reported the relation of BMI with proteinuria. Ali AA et al have reported prevalence of $10 \%, 9 \%$ and $23 \%$ of MAU in subjects with normal BMI, overweight and obese subjects respectively. They found significant association between BMI and MAU $(\mathrm{p}=0.014) \cdot \frac{14}{\cdot}$

Many studies done in recent past have reported that development and progression of diabetic nephropathy can be prevented by improving glycemic control, ${ }^{15} \mathrm{BP}$ control $^{16}$ and use of ACE inhibitors ${ }^{17}$ and or angiotensin II receptor blocker (ARB) antagonist. ${ }^{18}$

\section{Aims and Objectives}

1. To stratify the proportion of diabetic nephropathy as reflected by proteinuria, according to the duration of diabetesmellitus.

2. To identify the possible demographic, anthropometric and hemodynamic risk factor for the development of proteinuria in subjects of type 2 diabetesmellitus.

\section{Materials and Methods}

This study is an observational cross sectional study, which has evaluated the effect age of onset of disease, gender, obesity, blood pressure on occurrence of proteinuria in diabetes mellitus. After obtaining approval by the institutional ethical committee and informed consent form all subjects, 74 patients of type 2 diabetes mellitus attending endocrinology and Medicine Outpatient Department were enrolled for the present study.

Following inclusion and exclusion criteria were applied for selecting the subjects for the present study.

\section{Inclusion criteria:}

1. Already diagnosed diabetic adults aged 35-70 years attending OPD for routine follow up.

2. Patients on either diet therapy of oral hypoglycaemic agent (OHA) treatment.

\section{Exclusion criteria:}

1. Newly diagnosed patients of diabetes mellitus were not included in the study.

2. Patients on dialysis, laxative, fluid infusion.

3. Patients presenting with acute illness like fever, diarrhea.
4. Any operative procedure done in past one month.

Information on age, sex, height, weight, systolic, diastolic blood pressure and body mass index were obtained. Family history of diabetes and duration of diabetes was also recorded.

\section{Biochemistry measurements}

Blood sample collection: After obtaining informed and written consent, total $4 \mathrm{ml}$ of fasting venous blood was collected by venipuncture of cubital vein using flashback needle in following vacutainers:

1. $2 \mathrm{ml}$ of blood was collected in fluoride vacutainer forblood glucose estimation.

2. $2 \mathrm{ml}$ was transferred to plain vacutainer for estimation of Serum urea, creatinine, uric acid and serumelectrolyte.

Blood Fluoride vacutainer was mixed properly and that in plain vacutainer was allowed to clot at $37^{\circ} \mathrm{C}$ for $20 \mathrm{~min}$. Plain and fluoride vacutainer was centrifuged for $15 \mathrm{~min}$ at $3,000 \mathrm{rpm}$ and aliquots of serum and plasma was immediately analyzed for urea, creatinine, uric acid, electrolyte and glucose respectively.

\section{Method of assessment of various biochemical profile:}

1. Fasting plasma glucose, urea, creatinine was analyzed on TransAsia XL-640, a fully automated system using GOD-POD (glucose oxidaseperoxidase) method, Urease method, Jaffe's kinetic methodrespectively.

2. Serum electrolyte was measured using ion selectiveelectrode.

Urine sample collection: Early morning urine sample was collected in clean container and was preserved with boric acid $(0.1 \mathrm{~g})$ for every $10 \mathrm{ml}$ of urine. Proteinuria (semi quantitative) was assessed using Dipstix and was confirmed with sulfosalicylic acidmethod.

Anthropometric measurements: Height to nearest centimeter without shoes was measured with a wallmounted ruler and weight to nearest $0.1 \mathrm{~kg}$ in light clothing was measured. Body mass index (BMI) was calculated by dividing weight $(\mathrm{Kg})$ by height squared $\left(\mathrm{m}^{2}\right)$.

Blood pressure measurement: BP was measured by mercury sphygmomanometer and a stethoscope. Mean value of duplicate measurement was recorded as blood pressure.

\section{Statistical analysis}

Obtained data was summarized as Mean and Standard deviation. Paired student t-test was used to compare mean values of continuous variable and chi square test statistic was used to compare all categorical variables. For all statistical comparisons, a $\mathrm{p}$ value $<0.05$ was considered as statistically significant.

\section{Results}

Findings in our study are as follows: 
Demographic, Clinical and biochemical characteristic of the study population: The mean duration of diabetes, FBG and BMI was significantly higher in the group with proteinuria compare to the group with no proteinuria. There was no significant difference of systolic blood pressure, diastolic blood pressure in proteinuric group compared to no proteinuricgroup.

Table 1: Demographic, Clinical and biochemical characteristic of the study population

\begin{tabular}{|c|c|c|c|}
\hline Variable & $\begin{array}{c}\text { Total } \\
(n=74)\end{array}$ & $\begin{array}{c}\text { No Proteinuria } \\
(n=56)\end{array}$ & $\begin{array}{c}\text { Proteinuria } \\
(n=18)\end{array}$ \\
\hline Age & $51.9 \pm 10.8$ & $51.5 \pm 10.8$ & $52.9 \pm 10.9$ \\
\hline BMI & $26.6 \pm 3.5$ & $26.2 \pm 3.4$ & $27.8 \pm 3.6^{*}$ \\
\hline SBP & $140.6 \pm 13.5$ & $141.0 \pm 13.6$ & $139.4 \pm 13.4$ \\
\hline$\overline{\mathrm{DBP}}$ & $88.7 \pm 7.4$ & $88.6 \pm 7.7$ & $88.7 \pm 6.6$ \\
\hline FBG & $136.8 \pm 50.1$ & $126.0 \pm 39.7$ & $170.6 \pm 64.1 * *$ \\
\hline \begin{tabular}{|l|}
$\begin{array}{l}\text { Duration } \\
\text { (years) }\end{array}$ \\
\end{tabular} & $7.84 \pm 6.9$ & $6.5 \pm 6.1$ & $11.7 \pm 7.8^{*}$ \\
\hline
\end{tabular}

The mean age of patients with proteinuria though higher compared to the group without proteinuria the difference was not found to be statistically significant (Table 1).

Frequency of proteinuria in relation to body mass index (BMI): Prevalence of proteinuria as stratified by BMI is presented in Table 2. There was no participant who was underweight in our study group and out of total $27(36.5 \%)$ normal weight participants, $77.7 \%$ $(21 / 27)$ had no proteinuria and $22.3 \%$ (6/27) hadproteinuria.

Table 2: Prevalence of proteinuria as stratified by BMI

\begin{tabular}{|c|c|c|c|}
\hline BMI & $\begin{array}{c}\text { Total } \\
(\mathbf{n}=74)\end{array}$ & $\begin{array}{c}\text { No } \\
\text { proteinuria } \\
(\mathbf{n}=56)\end{array}$ & $\begin{array}{c}\text { Proteinuria } \\
(\mathbf{n}=18)\end{array}$ \\
\hline
\end{tabular}

Proteinuria in relation to blood pressure categories:

\begin{tabular}{|l|c|c|c|}
\hline $\begin{array}{l}\text { Underweight } \\
(<18.5)\end{array}$ & None & - & - \\
\hline $\begin{array}{l}\text { Normal } \\
(18.5-24.9)\end{array}$ & $27(36.5 \%)$ & $21(77.7 \%)$ & $6(22.2 \%)$ \\
\hline $\begin{array}{l}\text { Pre- obese } \\
(25-29.9)\end{array}$ & $33(44.6 \%)$ & $27(81.8 \%)$ & $6(18.2 \%)$ \\
\hline $\begin{array}{l}\text { Obese } \\
\geq 30)\end{array}$ & $14(18.9 \%)$ & $8(57.1 \%)$ & $6(42.9 \%)$ \\
\hline
\end{tabular}

Total $33(44.6 \%)$ participants were pre-obese out of which $81.8 \%(27 / 33)$ had no proteinuria and $18.2 \%$ $(6 / 33)$ had proteinuria. Total $14(18.9 \%)$ participants were obese out of which $57.1 \%$ (8/14) did not have proteinuria while $42.9 \%$ (6/14) hadproteinuria.

Proteinuria in relation to fasting plasma glucose: Prevalence of proteinuria as stratified by FPG is presented in Table 3. Out of total 20 (27\%) participants who had normal FPG, 90\% (18/20) had no proteinuria and $10 \%(2 / 20)$ had proteinuria.

Table 3: Prevalence of proteinuria stratified by FBG

\begin{tabular}{|l|c|c|c|}
\hline \multicolumn{1}{|c|}{ FBG } & $\begin{array}{c}\text { Total } \\
(\mathbf{n = 7 4})\end{array}$ & $\begin{array}{c}\text { No proteinuria } \\
(\mathbf{n = 5 6})\end{array}$ & $\begin{array}{c}\text { Proteinuria } \\
(\mathbf{n = 1 8})\end{array}$ \\
\hline $\begin{array}{l}\text { Normal } \\
(<110)\end{array}$ & $20(27 \%)$ & $18(90 \%)$ & $2(10 \%)$ \\
\hline $\begin{array}{l}\text { IFG } \\
(110-125)\end{array}$ & $17(23 \%)$ & $16(94.1 \%)$ & $1(5.9 \%)$ \\
\hline $\begin{array}{l}\text { DM } \\
(\geq 126)\end{array}$ & $37(50 \%)$ & $22(59.5 \%)$ & $15(40.5 \%)$ \\
\hline
\end{tabular}

17/74(23\%) participants were having impaired fasting glucose (IFG) out of which $94.1 \%$ (16/17) had no proteinuria and $5.9 \%(1 / 17)$ had proteinuria. Total 37 participants showed FPG 126 or more $\mathrm{mg} / \mathrm{dl}(\mathrm{DM})$ out of which 22/37(59.5\%) showed no proteinuria but 15/37(40.5\%) showed proteinuria.

Table 4: Proteinuria in relation to blood pressure categories

\begin{tabular}{|l|c|c|c|c|c|}
\hline BP categories & SBP & DBP & $\begin{array}{c}\text { Total } \\
(\mathbf{n = 7 4})\end{array}$ & $\begin{array}{c}\text { No proteinuria } \\
(\mathbf{n = 5 6})\end{array}$ & $\begin{array}{c}\text { Proteinuria } \\
(\mathbf{n = 1 8})\end{array}$ \\
\hline Optimal & $<120$ & $<80$ & Nil & - & - \\
\hline Normal & $120-129$ & $80-84$ & $3(4.9 \%)$ & $2(66.7 \%)$ & $1(33.3 \%)$ \\
\hline Pre HTN & $130-139$ & $85-89$ & $3(4.1 \%)$ & $1(33.3 \%)$ & $2(66.7 \%)$ \\
\hline HTN & & & & & \\
\hline Grade I & $140-159$ & $90-99$ & $34(45.9 \%)$ & $31(91.1 \%)$ & $3(8.9 \%)$ \\
\hline Grade II & $160-179$ & $100-109$ & $30(40.5 \%)$ & $21(70 \%)$ & $9(30 \%)$ \\
\hline Grade III & $\geq 180$ & $>110$ & Nil & - & - \\
\hline $\begin{array}{l}\text { Isolated } \\
\text { HTN }\end{array}$ & $\geq 140$ & $<90$ & $04(5.4 \%)$ & $1(25 \%)$ & $3(75 \%)$ \\
\hline
\end{tabular}

None of the participants had optimal BP in our study group. Maximum percentage of patients who showed proteinuria because of BP was seen in patients having "isolated systolic hypertension" where $75 \%$ (3/4) showed proteinuria compared to $25 \%$ (1/4) who did not had proteinuria. This was followed by pre- 
hypertension group where $66.7 \% \quad(2 / 3)$ showed proteinuria and $33.3 \%(1 / 3)$ had no proteinuria.8.9\% (3/34) patients with grade I hypertension and 30\% (9/30) patients with grade II hypertension showed proteinuria (Table 4).

Effect of duration of diabetes on frequency ofproteinuria: Fig. 1 represents the relation of duration of diabetes on occurrence of proteinuria. There was clear association seen in frequency of proteinuria with the duration of diabetes. $45 \%$ of patients who had diabetes for more than 10 years developed proteinuria as compared to $35.7 \%$ and $10 \%$ patients who had proteinuria for 5-10 years and less than 5 years respectively.

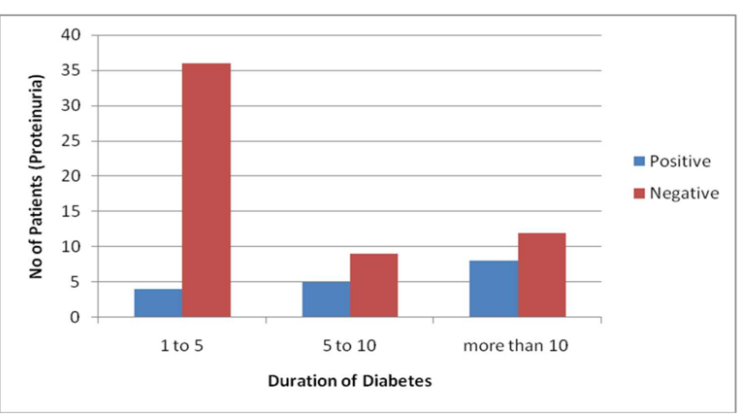

Fig. 1: Impact of duration of diabetes on proteinuria

\section{Discussion}

Present study was conducted to evaluate the effect of Age, BMI, SBP, DBP, FBG and duration of diabetes on frequency of proteinuria among type 2 diabetes mellitus patients attending medicine and endocrine OPD. Mean values of FBG, duration of diabetes and BMI were statistically significantly higher in proteinuria category of patients compared to no proteinuria category, but the mean values of SBP, DBP and Age were not found to be statistically significantly different in two categories of patients. On stratification of these values it was found that obesity, as stated by higher BMI and uncontrolled diabetes as stated by higher FBG, BP, duration of diabetes has impact on frequency of proteinuria.

Effect of duration of diabetes on frequency of proteinuria: In our study $45 \%$ of patients who had diabetes for more than 10 years developed proteinuria as compared to $35.7 \%$ and $10 \%$ patients who had proteinuria for 5-10 years and less than 5 years respectively. Our finding is agreeing with the findings of many other studies done in past. Varghese A et al have reported longer duration of diabetes in microalbuminuric category compared to normoalbuminuric category $(\mathrm{p}<0.001) .{ }^{19}$ In yet another study done by Dimple et al majority of the patients who developed proteinuria $(62.5 \%)$ had diabetes of more than 10 years. ${ }^{20}$

Effect of FBG on frequency of proteinuria: The mean fasting blood glucose of patients with proteinuria was $170.6 \pm 64.1$ compared to FBG of $126.0 \pm 39.7$ in patients with no proteinuria in our study group. This finding is consistent with finding of Varghese A et al where they have reported significant higher fasting plasma glucose in microalbuminuric group compared to normoalbuminuric group. ${ }^{19}$

The higher blood glucose in proteinuria category denotes uncontrolled diabetes and poor compliance to therapy. In our study fasting blood glucose is taken as a marker of blood glucose control in diabetic patients as $\mathrm{HbA1c}$ could not be done due to technical reasons and this is a limitation of our study.

Effect of BMI on frequency of proteinuria: In our study higher BMI is associated with higher frequency of proteinuria (42.9\% vs $22.2 \%$ in obese and normal BMI respectively). This finding is consistent with the result of Mokdad AH et al, Sheikh SA et al and Farahat TM et al, ${ }^{21-23}$ but is disagreeing with the result of Chowta $\mathrm{NK}^{24}$ who has not shown any effect of BMI on frequency of proteinuria in type II DM patients.

Effect of BP on frequency of proteinuria: Stratification of hypertension in our study group has shown that higher percentage of patients of isolated systolic hypertension (75\%) have developed proteinuria. Finding of this study is agreeing with the study conducted by Stratron IM et $\mathrm{al}^{25}$ who found that systolic blood pressure was significantly higher in those who progressed to incipient and overt diabetic nephropathy.

Our study has shown $8.9 \%$ and $30 \%$ of patients having grade I and grade II hypertension have developed proteinuria. Frequency of proteinuria in grade I hypertension in our study group is much lower compared to frequency of proteinuria in similar study subject in a study done by Tefera $\mathrm{G},{ }^{13}$ In our study $66.7 \%$ patients of prehypertension category of blood pressure have shown proteinuria. In another similar study done by Tefera $\mathrm{G}$ only $43.4 \%$ patients of isolated systolic hypertension category of patients had proteinuria $^{13}$. Higher percentage of proteinuria in prehypertension category in our study group may be due to the fact that patients were on irregular treatment and uncontrolled diabetes as assessed by high fasting plasma glucose level.

Effect of Age on frequency of proteinuria: The mean age of patients of type $2 \mathrm{DM}$ who had proteinuria was $52.9 \pm 10.9$ years which is similar to the mean age of patients of $54.0 \pm 10.5$ years observed in a study done by Vijay $\mathrm{V}$ et al. ${ }^{26}$

\section{Conclusion}

Proportion of proteinuria among type 2 DM patients in our study was $24.32 \%$. Significant predictors of proteinuria included BMI, FBG, BP and duration of diabetes mellitus. To reduce the occurrence of diabetic nephropathy, early measurements should be taken to control obesity, blood pressure and blood glucose. This will reduce the morbidity associated with this disease to a considerable extent and will improve life expectancy 
of diabetic patients.

\section{References}

1. USRD (2004) United States Renal Data System. Website: www.usrd.org.

2. Parvins H, Chaturvedi N, Carlo Viberti G. Does microalbuminuria predict diabetic nephropathy. Diabetic Care 2002;25:406-407.

3. Madaan H, Agrawal P, Garg R, Sachdeva A, Patra SK, NairR. Prevalence of diabetes mellitus in rural population of district Sonepat, India. Int J of Med Sci and Pub Health 2014;3(1):248-51.

4. Jia W, Gao X, Pang C. Prevalence and risk factors of albuminuria and chronic kidney disease in Chinese population with type 2 diabetes and impaired glucose regulation. Shanghai diabetic complications study (SHDCS) Neph Daily Transp 2009;24:3724-31.

5. Imai E, Matsuo S, Makino H. A chronic kidney disease Japan Cohort (CKD-JAC) study: design and methods. Hypertens Res 2008;31(6):980-88.

6. Leehey DJ, Kramer HJ, Daoud TM. Progression of kidney disease in type 2 diabetes beyond blood pressure control: an observational study. BMC Nephrol 2005;8:2.

7. Viswanathan V, Tilak P, Kumpatla S. Risk factors associated with the development of overt nephropathy in type 2 diabetes patients: A 12 year observational study. Indian J Med Res 2012;136:46-53.

8. Rossing P, Hougaard P, Parving HH. Risk factors for development of incipient and overt diabetic nephropathy in type 1 diabetic patients. Diabetic Care 2002;25:859-64.

9. Kohler KA, Mc Clellan WM, Zeimer D, Kleinbacim DG. Risk factors for microalbuminuria in black Americans with newly diagnosed type 2 diabetes. American Journal of Kidney Disease 2000:36;903-13.

10. Nelson RG, Knowler WC, Pettitt DJ, Saad MD, Bennett PH. Diabetic kidney disease in Pima Indians. Diabetic care 1993;Jan 16(1):335-41.

11. Unnikrishnan R, Rema M, Pradeepa R, Deepa M. Prevalence and risk factors of diabetic nephropathy in an urban south Indian population. Diabetes Care 2007;30:2019-24.

12. Schmitz A, Vaeth M. Microalbuminuria:A major risk factor in non-insulin dependent diabetes. A 10 year follow up study of 503 patients. Diabet Med 1988;5:126-34.

13. Girum Tefera. Determinants of proteinuria among type 2 diabetic patients at shakiso health centre, Southern Ethiopia: a retrospective study. Advances in Diabetes and Metabolism 2014;2(3):48-54.

14. Ali AA, Lami FHA. Prevalence and determinants of microalbuminuria among type 2 diabetes mellitus patients, Baghdad, Iraq, 2013. Saudi J Kidney Dis Transpl 2016;27(2):348-55.

15. UK Prospective Diabetes Study (UKPDS) Group. Intensive blood glucose control with sulphonyl ureas or insulin compared with conventional treatment and risk of complications in patientrs with type 2 diabetes (UKPDS 33). Lancet 1998;352:837-53.

16. Weidmann P, Schneider M, Bohlen L. Therapeutic efficacy of different antihypertensive drugs in human diabetic nephropathy: an update meta-analysis. Nephrol Dial Transplant 1995;10:39-45.

17. Lewis EJ, Hunsicker LG, Bain RP, Rohde RD. The effect of angiotens in converting enzyme inhibitor on diabetic nephropathy. N Engl J Med 1993;329:1456-
62.

18. Parving HH, Lehnert H, Brochner-Mortensen J. The effect of irbesartan on the development and progression of diabetic nephropathy in patients with type 2 diabetes. N Eng 1 JMed 2001;345:870-8.

19. Varghese A, Deepa R, Rema M, Mohan V. Prevalence of Microalbuminuria in type 2 diabetes mellitus at a diabetes centre in Southern India. Postgrad Med J 2001;77:399-402.

20. Dimple, Arora V, Arora M. 1Prevalence and determinants of proteinuria in type 2 diabetes mellitus. Pak J Physiol 2015;11(3):35-7.

21. Mokdad AH, Ford ES, Bowman BA. Prevalence of obesity-related health risk factors, 2001. JAMA 2003;289:76-9.

22. Sheikh SA, Baig JA, Iqbal T. Prevalence of microalbuminuria with relation to glycemic control in type 2 diabetic patients in Karachi. J Ayub Med Coll Abbbottabad 2009;21:60-7.

23. Farahat TM, Elasees GK, Gazareen SS, Elsayed TI. Prevalence of proteinuria among type 2 diabetic patients in Menoufia governorate, Egypt. Menoufia Medical Journal 2014;27:363-71.

24. Chowta NK, Pant P, Chowta MNP. Microalbuminuria in diabetes mellitus: Association with age, sex, weight, and creatinine clearance. Indian J Nephrol 2009;19:536.

25. Stratton IM, Adler AI, Neil HA. Association of glycaemia with macrovascular and microvascular complications of type 2 diabetes (UKPDS 35): prospective observational study. BMJ 2000;321:40512.

26. Vijay V, Snehlata C, Ramchandran A, Vishwanathan M. Prevalence of proteinuria in non-insulin dependent diabetes. J of Assoc Physicians India 1994;42(10):7924. 